\title{
Modelling of underground objects and geological-tectonic structures from a point cloud: application of the developed models in studies of geodynamic processes
}

\author{
Damian Kasza ${ }^{1, *}$ \\ ${ }^{1}$ Wrocław University of Science and Technology, Faculty of Geoengineering, Mining and Geology, 27 Wyb. Wyspiańskiego St., \\ 50-370 Wrocław, Poland
}

\begin{abstract}
At present, techniques of terrestrial laser scanning are one of the most popular survey methods. They allow for fast and non-invasive data acquisition even up to several tens of thousands points per minute. Apart from high precision and measurement efficiency, one of its assets is the possibility of working in objects with natural or artificial light. Due to this, the method may be successfully used in activities related e.g. with the surveying of the present state of underground excavations. The basic product derived from laser scanning measurements is a point cloud. This set is the input data for the construction of a 3D object with a closed surface, e.g. a mesh network. This paper presents the results of inventory works performed in a complex of underground excavations below Książ Castle in Lower Silesia (SW Poland). Based on a point cloud acquired during the measurements, a 3D model of the excavations was constructed. Open source software - MeshLab - was used in the modelling. The high-resolution, calibrated metric model of the underground excavations allowed for a macroscopic recognition of the position of the main tectonic structures cutting the space of the underground excavations. The obtained model was supplemented with the results of earlier geodetic and geological surveys, performed in 20132015. The generated model of the geological structure in the study area is an element supporting the interpretation of kinematic activity of the rock massif registered by the instruments of the SRC PAS Geodynamic Laboratory in Książ.
\end{abstract}

\section{Introduction}

Studies of the natural environment are a key to recognise the mechanisms of processes taking place within it. This particularly applies to Earth Sciences: geology, geophysics, geochemistry, etc. Continuous measurements of displacements performed by permanent GNSS receivers or registered by seismological observatories are good examples. The data that they supply are the basis for the analysis and interpretation of phenomena such as displacements of the upper layers of the lithosphere or effects caused by earthquakes.

However, individual study results are never sufficient enough. Presentation of the modelled phenomena requires a virtual image of the environment in which the given processes take place. This requires the use of digital models of land surface or the upper parts of the lithosphere from soundings or from analysis of material from deep boreholes.

In time of developing computer tools, projections of numerical surfaces of Earth's globe constructed with satellite photographs, data from laser scanning and photogrammetric images using unmanned aerial vehicles attain an increasing number of applications. Terrestrial laser scanning belongs to such new techniques. Being used in an increasingly wider spectrum of possibilities $[1,2]$, it allows for obtaining extremely precise reflections of the scanned objects/surfaces in a virtual space.

The paper presents the results of studies performed in the underground object "Książ" (Lower Silesia, SW Poland). They were focused on constructing a model of the underground excavations with determining the position of tectonic structures, i.e. discontinuity surfaces visible in their space.

\section{Study area}

The complex of underground corridors "Książ" was constructed directly below the courtyard of the Książ Castle near Wałbrzych (Fig. 1). The corridors were excavated during the Second World War in 1943-1945. According to the existing documents, the object was part of a Nazi secret military project with the cryptonym S3 "Riese" [3-5], which was aimed at the construction of a series of underground objects in Książ and in the Sowie Range (the Sudetes). Their destination remains unknown, most probably they were supposed to function as laboratories and/or armament objects. 


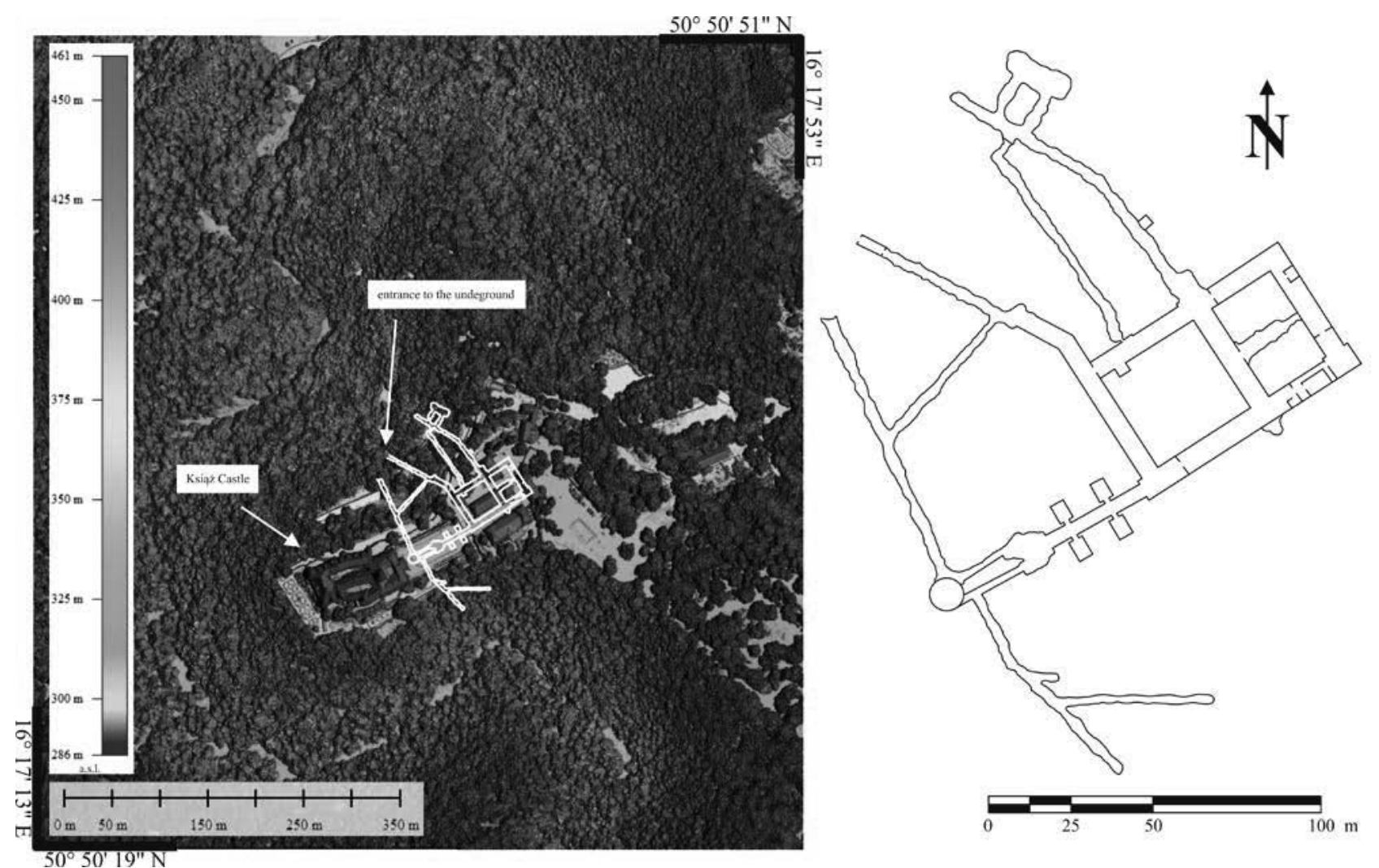

Fig. 1. Plan of underground corridors of the "Książ" object [6].

Since the 1970-ties, the underground corridors at Książ play the role of a laboratory belonging to the Polish Academy of Sciences (PAS). At present it houses the Seismological Observatory of the Institute of Geophysics (Polish Academy of Sciences) and the Geodynamic Laboratory, belonging to the Space Research Centre of the Polish Academy of Sciences (GL $\mathrm{SRC)}$.

The "Książ" object is located in the centre of a structural unit known as the Swiebodzice Basin. The entire space of the corridors was excavated within a sedimentary rocks known as the Książ Formation, which is Late Devonian to Early Carboniferous in age. The Formation includes conglomerates, with the clasts dominated by gneisses, granite-gneisses and light grey granites [7-12].

The unique properties of the Książ massif (nonpermeable rocks, dense fault network) allow for registering subtle effects of tectonic phenomena by sets of GL SRC measurement equipment: permanent GNSS stations, quartz horizontal pendulums, water-tube tiltmeters, vacuum interference extensometer and TM-71 crack gauge [11, 13-21].

\section{Measurements with terrestrial laser scanning technique}

The concept of measurements using terrestrial laser scanners is based on the measurement of distances and angles (both horizontal and vertical) in relation to the measurement point. Based on these three elements the position of the measured point in space is determined in the scanner local system. By tying the scanner measurement site to the grid point, it is possible to align the obtained measurements to global coordinates. A point cloud with a given density is obtained from the measurements. Single measurement sites of the scanner may be connected by equivalent reference points (at least 3). The reflection coefficient is an additional data obtained during measurement with a laser scanner; its value depends on the type of material (including physical properties), of which the measured object (point) is composed.

A Leica ScanStation C10 impulse scanner was used during the survey in Książ (Tab. 1). Earlier stabilised points of the horizontal grid were used as reference points for connecting the measurement sites (Fig. 2) [19, 22]. Due to the large dimensions of the surveyed excavations and an adequate distribution of the grid points, the average errors of the position of the measured points were minimized. Connection of particular sites was made in the Leica Cyclone environment. The resulting point cloud was aligned to the PL2000 zone 5 system through four points located in front of the entrance to the underground excavations (coordinates determined based on RTK GPS measurements).

\section{Data analysis}

A large amount of the collected data and high expectations regarding the specificity of the constructed model determined the need to seek a highly effective 
method of data processing allowing for precise reconstruction of the scanned surfaces. Open source software - MeshLab [23] - was selected for work with the point cloud. Its assets included e.g. a large number of data formats - both input and output data, several algorithms of constructing 3D models, processing millions of point datasets and a wide array of editing tools. Among the methods of constructing models available in the software functions, the out-of-core Poisson Surface Reconstruction was used in the analysis.

Table 1. Scanning parameters.

\begin{tabular}{|c|c|}
\hline Number of sites & 43 \\
\hline Scanning resolution & $5 \times 5 \mathrm{~cm}$ on a distance of \\
$50 \mathrm{~m}$
\end{tabular}

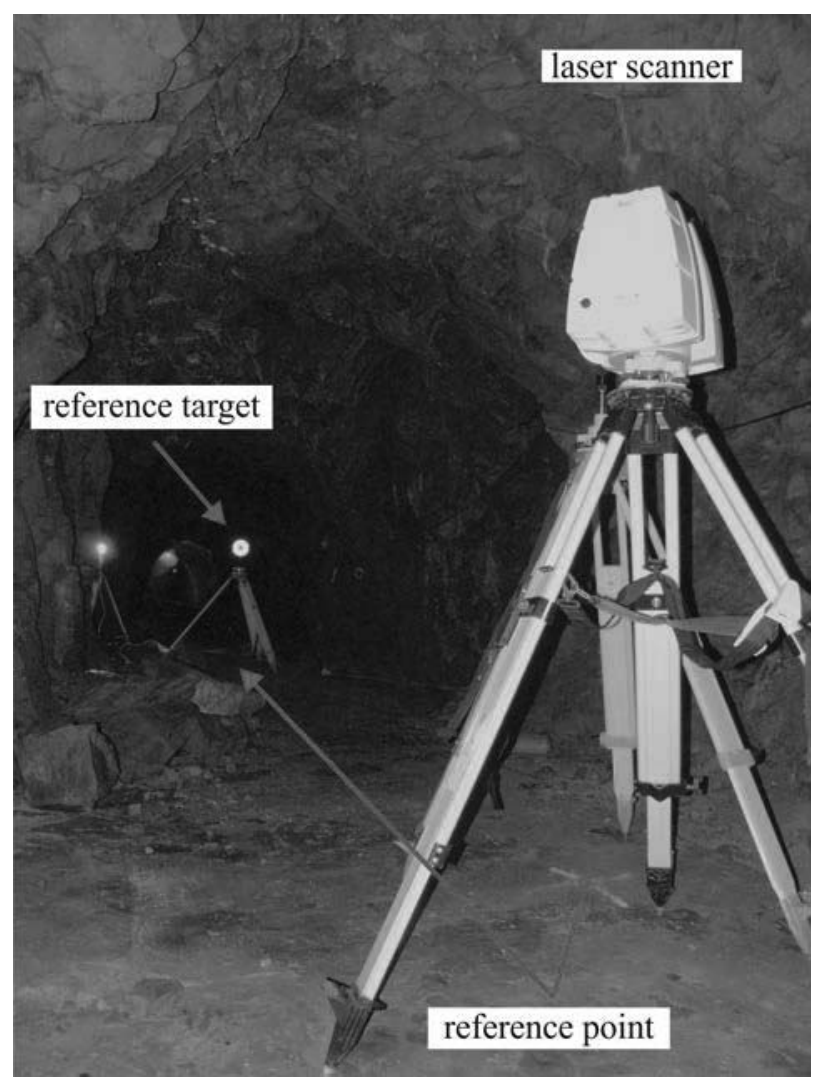

Fig. 2. Scanner measurement site.

\subsection{Poisson Surface Reconstruction Algorithm}

Solution of the problem of mesh type surfaces from a point cloud has been described in detail by Kazhdan et al. [24] and Bolitho et al. [25]. These authors presented the reconstruction of a surface from a point cloud as a solution of the Poisson problem in space. It is based on the transformation of a point set into a spatial continuous vector field, followed by finding a scalar function, whose gradients best fit to the vector field, and constructing a specific isosurface. The advantage of this method is data processing as a single dataset (without subdivision into local zones and their further joining to obtain a complete model). Besides, the algorithm is resistant to errors derived from the imprecision of stacking the scanner sites or lack of data (points) in some regions [26].

During the surface reconstruction process, based on the Poisson algorithm, MeshLab presents the data structure as an octree with a given depth. The larger depth value results in a more precise output model. This results with increasing the duration of the process and utilization of the computer resources. Application of multi-level data streaming during surface construction using the Poisson Surface Reconstruction algorithm, presented by Bolitho et al. [27], has allowed for work with large datasets but has generally increased the effectiveness of the process at restricted resources (processing power, computer memory) without loss of precision of the constructed models.

\subsection{Construction of a 3D model for the "Książ" object}

A ready-made packet of raw measurement data required indispensable initial processing before the construction of the mesh model. Points located beyond the underground excavations (fragments of land surface, vegetation, etc.) and noise, i.e. points located in direct proximity of the scanned excavations but not being part of them, were removed manually in the first step. Additionally, the Poisson-disk sampling [28] filter was applied to the dataset, which allowed for unifying the point cloud (the minimal distance between the neighbouring points was determined at the level of 1 $\mathrm{cm})$. The result of this operation was decreasing the point density in direct proximity of the measurement sites, and therefore increase of the degree of sustainable distribution of points of the scanned surface.

After these operations, precision of the constructed mesh models was tested with regard to the applied parameters of the Poisson Surface Reconstruction algorithm. The most important among them, Octree depth, determined the degree of recurrent subdivision of the octree structure, and therefore larger specificity of the constructed mesh model. For values of this parameter exceeding 14, significant improvement of the quality of the obtained models was not observed (Tab. 2). The remaining coefficients influencing the degree of computer resources utilization, the minimal number of points visible in the tree branch and the method of isosurface compensation have been retained with default values $(8 ; 1 ; 1)$.

The process of mesh surface construction for depth coefficient at 14 lasted for about $2 \mathrm{~h}$ (the computer used was a 6th generation Intel ${ }^{\circledR}$ Core $^{\mathrm{TM}}$ i7-6700HQ processor, 32 GB RAM $1600 \mathrm{MHz}$, SSD hard disk). The constructed mesh surface was composed of almost 95 million triangles. The effect of this operation is presented in Fig. 3. 
Table 2. Quantitative results of mesh model reconstruction depending on the applied depth value parameter.

\begin{tabular}{|c|c|c|c|c|}
\hline $\begin{array}{c}\text { Number of } \\
\text { points }\end{array}$ & Depth & $\begin{array}{c}\text { Number of } \\
\text { triangles }\end{array}$ & $\begin{array}{c}\text { Duration of model } \\
\text { construction } \\
\text { [hours:minutes:seconds] }\end{array}$ & $\begin{array}{c}\text { Utilisation of memory resources } \\
\text { (peak memory) [MB] }\end{array}$ \\
\hline \multirow{5}{*}{61698648} & 10 & 407910 & $00: 08: 25$ & 271.54 \\
\cline { 2 - 5 } & 11 & 1706185 & $00: 09: 10$ & 279.17 \\
\cline { 2 - 5 } & 12 & 7024488 & $00: 14: 13$ & 295.54 \\
\cline { 2 - 5 } & 13 & 27986164 & $00: 43: 39$ & 855.00 \\
\cline { 2 - 5 } & 14 & 94932204 & $01: 56: 00$ & $2,740.00$ \\
\cline { 2 - 5 } & 15 & 94598409 & $02: 50: 49$ & $1,950.00$ \\
\cline { 2 - 5 } & 17 & 94403184 & $03: 31: 50$ & $3,510.00$ \\
\cline { 2 - 5 } & 18 & 94235574 & $06: 19: 50$ & $5,870.00$ \\
\hline
\end{tabular}

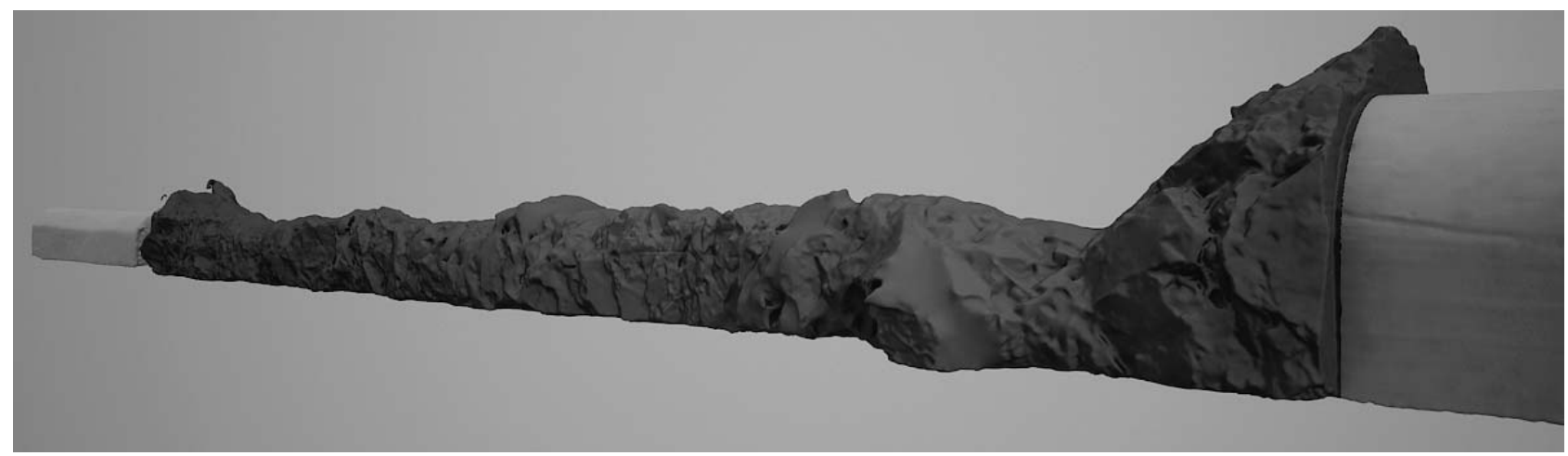

Fig. 3. Visible fragment of the model of entrance adit with visible surfaces of concrete casing (grey) and unprotected part of corridor (black).

\section{Results}

The mesh structure constructed from the measurement points is a metric product approximately corresponding to the present state of the excavations. Based on the assumption of a precise and correct reflection of the structure of the corridors that have not been rebuilt, an attempt was made to recognise discontinuity zones, whose presence was determined during earlier structural investigations and observation of sidewalls during scanning of the excavations.

Correlation of the constructed model with the results of in situ measurements of the tectonic structures [12, 22] has resulted in distinguishing the position of several tens of discontinuity zones. Application of Autodesk 3DS Max software for each dislocation zone resulted in determining study sites in the $3 \mathrm{D}$ space. The closed sites created Bézier type surfaces (Fig. 4) [22, 29], corresponding to fault surfaces cutting the excavation space.

For a fast acquisition of data on the azimuth of fault orientation and dip angle of a given fault, a plane had to be aligned to the given surface. Solution of this issue required the use of an algorithm worked out by Kasza et al. [19]. It assumes calculating a normal plane (1) in a Cartesian system, where the sum of squared distances between points (representing the fault position) to this plane is the smallest (2) [19]:

$$
0=X \cos (\alpha)+Y \cos (\beta)+Z \cos (\gamma)-p
$$

where $p$ is the distance of the plane to the beginning of the measurement system;

$$
S=\sum_{i=1}^{N} \delta_{i}^{2}\left(x_{i}, y_{i}, z_{i}\right)
$$

where $N$ is the number of measurement pickets for a given fault (peaks of a surface drawn in the 3D space).

The peaks of a 3D surface drawn for a given fault were attained as measurement points, whereas the beginning of the reference system was one of the three GPS points used for the calibration of the scanned object. As a result, values of dip and strike of planes representing the faults were calculated for each of the determined surfaces (Fig. 5). Calibration of the obtained image of fault orientation in a $2 \mathrm{D}$ space with earlier reports $[19,22]$ allowed to confirm the directional compatibility of the obtained projections for a given population of faults in the Książ underground space. 


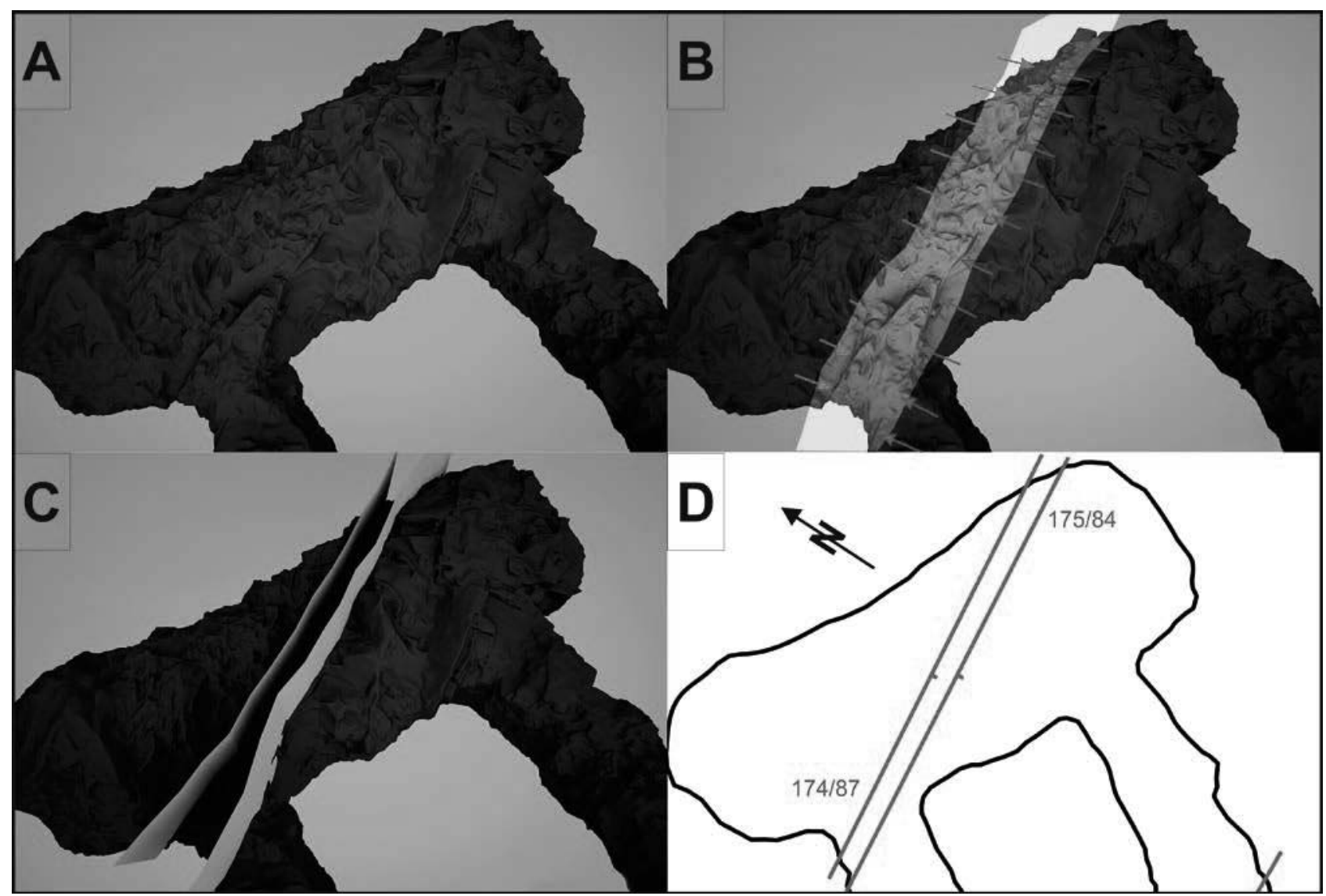

Fig. 4. The so called "Guardroom": A) 3D model as a mesh type structure; B), position of identified discontinuity surfaces;

C) generated models of the discontinuity surfaces (higher range surfaces); F) fragment of constructed geological sketch with marked discontinuity zones and calculated values of directional parameters.

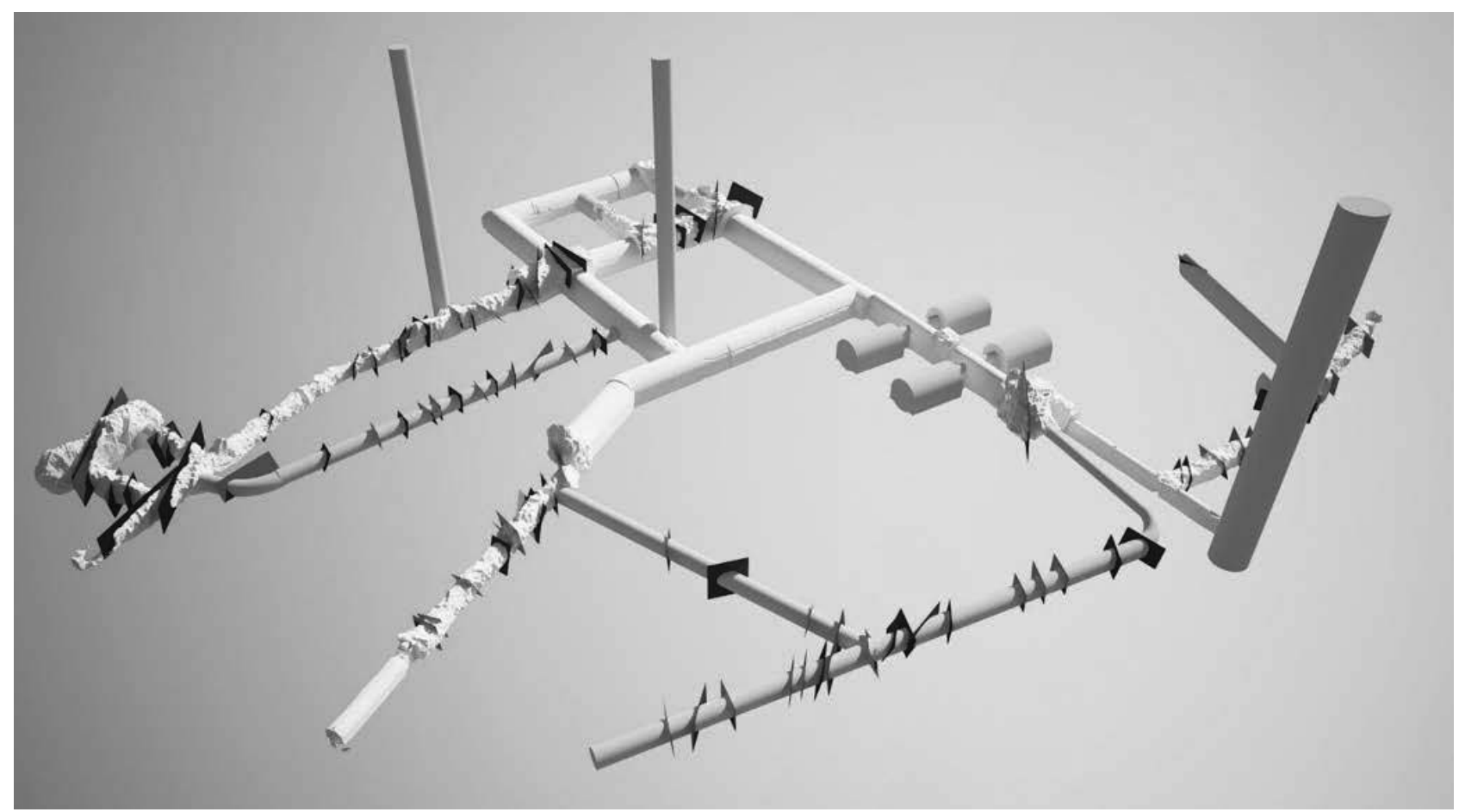

Fig. 5. 3D model of underground excavations below Książ Castle (grey and yellow) with marked position of the main discontinuity zones (blue). 


\section{Discussion}

Use of input data in form of a point cloud and MeshLab software has allowed for constructing a high-resolution metric model of the underground excavations at Książ. The applied algorithm used in the reconstruction of a mesh surface - Poisson Surface Reconstruction - turned out to be optimal at application of reconstruction depth at 14 (Tab. 2).

The further part of the study - generation of the course of surfaces marking the discontinuity zones - has allowed to reconstruct the position of the main tectonic zones cutting the space of the underground excavations. Comparison of these results with earlier tachymetric surveying [22] has confirmed their compatibility.

The constructed model is a base for derived products such as maps or profiles. The large amount of data types, which may be recorded from the level of the MeshLab and 3DS Max environments allows for their use and further processing using other software, both commercial and open source.

\section{Conclusions}

Terrestrial laser scanning presently belongs to one of the fastest and most effective methods of acquiring information on the topography of underground objects. It allows for a precise method of reconstructing the scanned objects in a virtual space, and, moreover, their reference with existing numerical reports.

The presented method of data processing and analysis indicates its usability in many aspects. It is a significant support in surveys related with geological documentation. Due to a unique possibility of observing the massif from inside (penetration of excavations) and conducting the presented surveys, it was possible to construct a digital spatial geological-tectonic model of the study area. Such projection of the massif in the region of Książ may become a valuable database for geodynamic investigations in GL SRC PAS. Knowledge on the distribution of discontinuity zones in the Książ massif will enable designing a kinematic model of the rock massif behaviour during the effects of tectonic phenomena registered by the GL SRC instruments [3032]. Moreover, the constructed high-resolution model may become a valuable element promoting such objects (natural or of anthropogenic origin) for visiting by tourists.

This work was financed by the Polish Statutory Research Grant no. 0402/0137/16 and Grant no. 0401/0128/17.

\section{References}

1. N.J. Rosser, D.N. Petley, M. Lim M., S.A. Dunning, R.J. Allison, Quarterly Journal of Engineering Geology and Hydrogeology, Vol. 38, 363-375, DOI:10.1144/1470-9236/05-008 (2005)

2. J. Mah, C. Samsona, S.D. McKinnonb, D. Thibodeauc, International Journal of Rock
Mechanics and Mining Sciences, Vol. 58, 111-117, doi:10.1016/j.ijrmms.2012.08.001 (2013)

3. M. Dudziak M., The secret of the Owl Mountains guidebook (JMK Publishing House, 1996, in Polish)

4. M. Aniszewski and P. Zagórski, 2006. Underground World of the Owl Mountains - Riese - Ksiąz Castle - Rüdiger (Technol Publishing House, 2006, in Polish)

5. K. Grudzińska and D. Kasza, Hereditas Minariorum, vol. 1, 113-123 (2014, in Polish)

6. CODGiK, Geodesic and Cartographic Documentation Center, Available online: http://www.codgik.gov.pl/, access date 5 November, 2017 (in Polish).

7. R. Marcinowski, J. Piotrowski, K. Piotrowska, Dictionary of Polish lithostratigraphic units (Polish Geological Institute, 2004, in Polish)

8. J. Oberc, Tectonics. Sudeten Mountains and adjacent areas (Geological Publishing House, Warszawa 1972, in Polish)

9. S.J. Porębski, Geol. Sudetica, XVI, No. 1, 101-192 (1981)

10. Z. Bełka and M. Narkiewicz, [In:] T. McCann (Ed.), The Geology of Central Europe. Volume 1: Precambrian and palaeozoic (The Geological Society of London, 383-410, 2008).

11. M. Kaczorowski and J. Wojewoda, Acta Geodynamica et Geomaterialia, 8, No. 3 (163), 249261 (2011)

12. D. Kasza, A. Kowalski, J. Wojewoda, M. Kaczorowski, E3S Web of Conferences 29, 00021 (2018)

13. M. Kaczorowski, Artificial Satellites, vol. 34, no. 3, 171-191 (1999)

14. M. Kaczorowski, Artificial Satellites, vol. 34, no. 3, 193-201 (1999)

15. M. Kaczorowski, Acta Geodynamica et Geomaterialia, 4, No. 4 (148), 109-119 (2007)

16. M. Kaczorowski, Reports on Geodesy, 85, 2, 79-86 (2008)

17. M. Kaczorowski, Acta Geodynamica et Geomaterialia, 6, No. 3, 369-381 (2009)

18. M. Kaczorowski, 16th International Symposium on Earth Tides, 1-5 September 2008, Jena, Bulletin d'Information des Marées Terrestres (BIM), 144, 11605-11613 (2009)

19. D. Kasza, M. Kaczorowski, R. Zdunek, R. Wronowski, Acta Geodynamica et Geomaterialia, 11, No. 3 (175), 225-234, DOI:10.13168/AGG. 2014.0011 (2014)

20. R. Zdunek, M. Kaczorowski, D. Kasza, R. Wronowski, Acta Geodynamica et Geomaterialia 11, No. 4 (176), 305-315, DOI:10.13168/AGG. 2014.0016 (2014)

21. M. Kaczorowski, P. Goluch, J. Kuchmister, K. Cmielewski, R. Zdunek, A. Borkowski, Acta 
Geodynamica et Geomaterialia, 12, No. 2 (178), 169-179, DOI:10.13168/AGG.2015.0012 (2015)

22. D. Kasza, Recent tectonic activity in aspect of stability of the Ksiaz Castle complex (PhD Thesis, Wrocław University of Science and Technology, 2016)

23. MeshLab, official website http://meshlab. sourceforge.net/, access date 22.06.2015

24. M. Kazhdan, M. Bolitho, H. Hoppe, [In:] Symposium on Geometry Processing, Alla Sheffer and Konrad Polthier (Editors), The Eurographics Association, 61-70, DOI: 10.2312/SGP/SGP06/061070 (2006)

25. M. Bolitho, M. Kazhdan, R. Burns, H. Hoppe, [In:] Advances in Visual Computing, Lecture Notes in Computer Science Volume 5875, Springer, 678-689, DOI: 10.1007/978-3-642-10331-5_63 (2009)

26. M. Kazhdan and H. Hoppe, ACM Transactions on Graphics, Vol. 32, No. 3, DOI: http://dx.doi.org/ $10.1145 / 2487228.2487237$ (2013)

27. M. Bolitho, M. Kazhdan, R. Burns, H. Hoppe, [In:] Symposium on Geometry Processing, 69-78 (2007)

28. M. Corsini, P. Cignoni, R. Scopigno, IEEE Transaction on Visualization and Computer Graphics, Volume 18, Number 6, 914-924 (2012)

29. M.S. Muhammad, M.T. Mahamood, C. Tae-Sun, IEEE International Conference on Acoustics, Speech and Signal Processing, 753-756, DOI: ieeecomputersociety.org/10.1109/ICASSP.2009.495 9693 (2009)

30. M. Kaczorowski, Acta Geodynamica et Geomaterialia, 2, No. 3 (139), 1-7 (2005)

31. M. Kaczorowski, Acta Geodynamica et Geomaterialia, 3, No. 3 (143), 79-84 (2006)

32. M. Kaczorowski, [In:] Earthquake Source Asymmetry, Structural Media and Rotation Effects, Springer-Verlag, Berlin, 493-520 (2006) 